\title{
Retributivism revisited
}

\author{
Nathan Hanna
}

(C) Springer Science+Business Media Dordrecht 2013

\begin{abstract}
I'll raise a problem for Retributivism, the view that legal punishment is justified on the basis of desert. I'll focus primarily on Mitchell Berman's recent defense of the view. He gives one of the most sophisticated and careful statements of it. And his argument is representative, so the problem I'll raise for it will apply to other versions of Retributivism. His insights about justification also help to make the problem particularly obvious. I'll also show how the problem extends to nonretributive justifications of punishment. I'll argue that Berman's argument makes a questionable assumption about the standard of justification that justifications of punishment must meet to be successful. If we think about what it takes to justify punishment and reflect on the intuitions that retributivists appeal to, it turns out that the intuitions aren't obviously up to the task.
\end{abstract}

Keywords Punishment · Justification · Retributivism

\section{Introduction}

I'll raise a problem for Retributivism, the view that the institution of legal punishment is justified on the basis of desert. ${ }^{1}$ I'll focus primarily on Mitchell Berman's (2008) recent defense of the view. I'll do this for two reasons. First, he gives one of the most sophisticated and careful statements of it. His argument is representative, so the problem I'll raise for it will apply to other versions of

\footnotetext{
${ }^{1}$ Not all views that have been called retributivist explicitly appeal to desert. But views that appeal to desert are-or at least are widely taken to be-paradigmatic (cf. Tadros 2011, p. 9). At any rate, the problem I'll raise will extend even to retributivist views that don't appeal to desert. This will become clear.
}

N. Hanna $(\bowtie)$

Department of English and Philosophy, Drexel University, 5044 MacAlister Hall,

3141 Chestnut Street, Philadelphia, PA 19104, USA

e-mail: nhanna@drexel.edu 
Retributivism. Second, his insights about justification help make this problem particularly obvious. I'll also briefly indicate at the end of the paper how the problem extends to non-retributive justifications of punishment. Throughout, I'll use the word "punishment" to mean "legal punishment."

I'll start by outlining Berman's argument. Then I'll formalize it and argue that it makes a questionable assumption about the standard of justification that justifications of punishment must meet to be successful. If we think about what it takes to justify punishment and reflect on the intuitions that retributivists appeal to, it turns out that the intuitions aren't obviously up to the task.

\section{Berman's argument}

According to Berman, punishment requires justification because there are apparent reasons against it. Attempts to justify punishment, he says, are attempts to respond to these reasons. He calls these reasons "demand bases." He says that attempts to justify acts or practices need only be "specific" in that they need only be "tailored" to particular demand bases. We justify acts and practices, he says, against specific doubts people raise about them. ${ }^{2}$ He contrasts this with a practice of "general" justification, which would require "a fruitless attempt to identify and respond to every conceivable objection" (p. 265; all references to Berman are to his 2008). He says that our practice of justification is specific because general justification is too demanding.

Among the most prominent demand bases for punishment, he says, is the fact that it inflicts suffering (I prefer to say harm, but I'll follow Berman). This fact about it is worrisome for obvious reasons, among them this: it seems intrinsically bad when people suffer. He tries to justify punishment against this demand basis by appealing to what he calls "the desert claim." 3

A person who unjustifiably and inexcusably causes or risks harm to others or to significant social interests deserves to suffer for that choice, and he deserves to suffer in proportion to the extent to which his regard or concern for others falls short of what is properly demanded of him. (p. 269)

For simplicity, he puts it like this: wrongdoers deserve to suffer on account of and in proportion to their blameworthy wrongdoing.

Berman assumes that the desert claim entails the claim that it's intrinsically good when wrongdoers suffer (p. 269; cf. Davis 1972; Moore 1993). He endorses a

\footnotetext{
2 John Kleinig (1973, p. 45) and John Gardner (1996, [2007], p. 95) make a similar point.

3 Technically, he tries to justify only what he calls "core" cases of punishment against this objection by appealing to the desert claim. He distinguishes between core and "peripheral" cases of punishment (p. 261). Core cases are those imposed on the guilty. Peripheral cases are those mistakenly imposed on the innocent. He takes punishment to be the union of core and peripheral cases. Justifying it, he says, requires justifying both cases. His justification of peripheral cases is consequentialist. Since I'm concerned primarily with Retributivism here, I'll focus on what he says about core cases. So I'll dispense with the core/peripheral distinction. However, my criticism of the retributivist portion of Berman's argument extends to the consequentialist portion. See the end of Sect. 4.2.
} 
standard retributivist strategy that defends the desert claim with thought experiments (p. 270; cf. Davis 1972; Kleinig 1973; Moore 1993). Consider a notorious Nazi. Most people, he thinks, would have the intuition that the Nazi deserves to suffer. Moreover, he thinks, they would have similar intuitions about similar cases. Given this, he takes the desert claim to have substantial support. This suffices, he says, to justify punishment against the fact that it inflicts suffering. He summarizes the argument as follows.

Thirty-odd years ago, Lawrence Davis succinctly adjudged the proposition that there is intrinsic value in wrongdoers' suffering "very likely" "on the grounds (a) that there is no convincing argument against it, and (b) that inclination to believe it seems widespread among the people whose moral intuitions constitute the main data we have for settling questions of value." Today's anti-retributivists are no closer to mounting a convincing counterargument ... while those expressing such a belief have swelled. We therefore seem entitled to conclude that [punishment is justified against the fact that it inflicts suffering], on account of the [desert claim]. (p. 271; cf. Davis 1972, p. 139)

Berman says that the desert claim has sufficient support to "cancel" the demand basis, i.e., show that it's false and that it poses no problem for punishment.

Next, I'll formalize Berman's argument. Then I'll discuss the intuitions he appeals to and I'll challenge a key premise.

\section{Formalizing the argument}

I'll consider two ways of formalizing Berman's argument. The first is simpler but conflicts with his view of justification. Considering it will help clarify his view of justification. This is crucial to identifying the problem I'll raise. Here's the first formulation.

1. Justification is specific. Punishment requires justification because it inflicts suffering and because it seems intrinsically bad when people suffer.

2. It is intrinsically good when wrongdoers suffer.

3. So, punishment is justified against the fact that it inflicts suffering.

For simplicity, I've omitted premises about desert. I'll incorporate them later.

It's important to see why this formulation is bad. The truth of 2 is purporting to do the justificatory work here. This makes the argument invalid, given Berman's take on justification. Here's why. Assume that 1 is true and that Berman is right that justification is a practice involving the giving of reasons in response to doubts. Consider a possible world $\mathrm{W}$ that has the same practice. Everyone in $\mathrm{W}$ has the intuition that 2 is false and that it's intrinsically bad when wrongdoers suffer. No one has intuitions that support 2, not even indirectly. Suppose that 2 is nevertheless 
true. Does this make 3 true? Not obviously, since no one in $\mathrm{W}$ has any reason to believe $2{ }^{4}$

One might respond that 2 does make 3 true but that no one in $\mathrm{W}$ knows this. In one sense of "justified" this may be right. But this isn't the sense at issue. The response is at odds with Berman's take on justification as a practice involving the giving of reasons in response to doubts. So construed, justification isn't just a matter of whether there are reasons against doubts. It's a matter of whether people recognize and give such reasons to one another in response to doubts. People in $\mathrm{W}$ object to punishment on the grounds that it's intrinsically bad when wrongdoers suffer. No one in $\mathrm{W}$ can give 2 as a reason that justifies punishment against this objection because no one in $\mathrm{W}$ has epistemic access to the fact that 2 is true. In the sense of "justified" that Berman is concerned with, acts and practices are justified only if the relevant agents can give a justification for them. No one in $\mathrm{W}$ can give 2 as a justification in this sense. I'll assume, along with Berman, that this is an important sense of justification and that debates over punishment's justifiability implicate it (p. 263). I take this assumption to be uncontroversial.

A better formulation is needed, then. First, I'll put the argument in terms of whether justification can be given for punishment rather than whether punishment is justified full stop. This emphasizes the sense of justification at issue. Second, we need premises saying that the needed reasons can be given: premises 5 and 6 below. Finally, I'll include premises about desert: premises 2 and 3 below. The reformulation avoids the problem with the first formulation.

The additions yield this.

1. Justification is specific. Punishment requires justification because it inflicts suffering and because it seems intrinsically bad when people suffer.

2. Wrongdoers deserve to suffer.

3. If wrongdoers deserve to suffer, then it is intrinsically good that they suffer.

4. So, it is intrinsically good that wrongdoers suffer. $(2,3)$

5. If good enough reasons can be given for 4 , then punishment can be justified against the fact that it inflicts suffering. (1)

6. Good enough reasons can be given for 4 .

7. So, punishment can be justified against the fact that it inflicts suffering. $(5,6)$

I take this to be a sufficiently accurate formulation. I'll challenge a key premise.

\section{Criticism}

I'll argue that Berman's case for 4 doesn't obviously satisfy the justificatory standard implicated in 6 (elsewhere, I've argued against 3; see Hanna in press b). A similar criticism applies to other versions of Retributivism that appeal to different

\footnotetext{
4 Of course, one might claim that 3 could be true in $\mathrm{W}$ for other reasons, reasons that could be substituted into 2 (e.g., that punishment has good consequences that outweigh the alleged badness of suffering). As long as we keep premise 1 and grant Berman's view of justification, though, it really doesn't matter what premise 2 is, so long as people can be in a similar epistemic position with respect to it.
} 
claims. ${ }^{5}$ It also applies to non-retributive justifications of punishment, as I'll discuss later.

\subsection{The value claim}

Call 4 the value claim. In this section, I'll explore some features of the intuitions that retributivists appeal to in its defense. These features are insufficiently appreciated and often overlooked. My aim is not to give a decisive argument against the value claim, just to raise some doubts about it. My ultimate target is 6 . In the next section, I'll show how my observations raise an important problem for 6 even if there's a good intuitive case for the value claim.

Berman endorses the standard retributivist argument for the value claim. It uses thought experiments. Imagine some horrible person. Retributivists say that most of us have the intuition that it's intrinsically good when such people suffer. John Kleinig (1973, p. 67) uses a notorious Nazi. Lawrence Davis (1972, p. 140) uses a movie villain who is "irremediably wicked to the core". Michael Moore (1987, 1993) uses several examples, including a fictional nobleman who brutally kills a child in front of its mother.

Retributivists don't provide support for their claim about what people's intuitions are here (cf. Braithwaite and Pettit 1990, p. 157). They assume that most people would share their intuitions about these cases. Maybe they're right. Still, it's not obvious how many people share their intuitions. ${ }^{6}$ It's easy to overestimate the popularity of our intuitions, especially when our intuitions are strong. Indeed, psychological studies have repeatedly confirmed the existence of a so-called false consensus effect, i.e., a widespread "general tendency to perceive a false consensus for one's opinions, evaluations, attributes, and behaviors" (Marks and Miller 1987, p. 75). This is important. We can't be too quick-as retributivists often are-to assume that others share our intuitions.

Another relevant feature of these intuitions is their strength. An intuition's strength affects its ability to justify belief (cf. Huemer 2005, p. 105). Retributivists often claim that the intuitions they appeal to are strong. Davis, Kleinig, and Moore all call them "deep" (Davis 1972, p. 140; Kleinig 1973, p. 67; Moore 1993, p. 25). But assuming that everyone who has these intuitions has them in a strong form is speculative. Some who have them voice serious doubts about them. Some retributivists take great pains trying to dispel these doubts (see, e.g., Moore 1987).

The thought experiments also elicit a narrow set of intuitions. These intuitions don't support the value claim because they aren't sufficiently general. At best, what the thought experiments show is that most people intuit that it's intrinsically good when moral monsters suffer. Showing that most people intuit that it's intrinsically good when wrongdoers suffer requires a broader range of cases (cf. Dolinko 1991,

\footnotetext{
5 One such claim: wrongdoers have no right not to be punished. Berman appeals to this claim to deal with a different demand basis: the claim that punishment would violate rights.

${ }^{6}$ I know of no studies that try to gauge intuitions about the value claim. But there are many studies gauging people's judgments about whether certain wrongdoers should be punished and about how seriously they should be punished. See, e.g., Robinson and Kurzban (2006-2007). For reasons I won't go into, I think these studies are at best of limited use for retributivists.
} 
pp. 556-557). Consider a minor wrong. Suppose Jack promised to remember his mom's birthday, but forgets and seriously hurts her feelings. This satisfies the criteria in Berman's unabbreviated desert claim (unjustifiable, inexcusable, causes or risks harm to others or to significant social interests, and displays insufficient regard or concern for others). ${ }^{7}$ But is it intrinsically good if Jack suffers for and in proportion to what he did? It's not obvious that most people would strongly intuit that it is. ${ }^{8}$ The same can be said of other more serious cases of wrongdoing, e.g., vandalism, burglary, etc. These acts also satisfy Berman's criteria. ${ }^{9}$

Another relevant feature of these intuitions is their stability. Calling them deep is presumably also meant to convey something about their firmness and persistence. But such intuitions can weaken or disappear in response to things like shifts in perspective. I'll illustrate. Take those who have the intuition that it would be intrinsically good that Jack suffer. Suppose that instead of imagining him, they were faced with him. He looks sad and tells them that he feels badly about what he did. With Jack suffering before them, would his suffering still seem intrinsically good to them? For some, I suspect it wouldn't. For some others, I suspect that the intuition would be weaker. ${ }^{10}$ Indeed, when faced with people like Jack, we often try to comfort them, downplay the wrong, and suggest ways to make up for it.

To gauge the reliability of these intuitions, we'd have to investigate their stability. If an intuition weakens or disappears due to such perspective shifts, this can be a reason to doubt it. Perhaps the shift reveals new information or helps one appreciate things one didn't sufficiently appreciate before. Considering things abstractly can make us overlook or fail to sufficiently appreciate important features of such cases. We may, for example, only be able to fully appreciate the badness of suffering up close. Considering things abstractly can make us focus too much on the wrongdoing and distract us from the nature of suffering and its impact. ${ }^{11}$ It's notable that two of the thought experiments above involve fictional characters. The other involves a historical (type of) person. Even when retributivists consider real examples, they're invariably considered at an intellectual distance.

To summarize, it's not obvious how widespread, general, strong, and stable the requisite intuitions are. To assess Berman's case for the value claim and his case for punishment, we need more information about people's intuitions. To avoid misunderstanding, let me emphasize again that I haven't argued that the value

\footnotetext{
7 If you're worried that Jack's forgetting is excusable, recall that he promised to remember and so should have taken steps to ensure that he would remember. Suppose he didn't take such steps.

${ }^{8}$ One might say that it would be good if Jack felt guilty and that it follows from this that it would be good if he suffered. I address this view elsewhere. See Hanna (2009, in press b). (Cf. Tadros 2011, pp. 41-59).

9 The obvious retort is that retributivists can just say that it's intrinsically good when perpetrators of serious wrongs suffer (thanks to an anonymous referee here). This misses the point, viz. that retributivists overlook important features of our intuitions here, and thereby oversimplify things. The retort doesn't improve on this, since it doesn't say what counts as serious. There are other problems with the retort, but since it isn't a good response to the problem I'll raise (this will become clear), I'll forego further comment.

10 Thanks to Katherine Valde for offering such a self-report about a similar case in discussion.

11 See Freiman and Nichols (2011, pp. 127-132) for literature on related phenomena and discussion of debates over the comparative reliability of intuitions about abstract and concrete cases.
} 
claim is false. Nor have I argued that people don't or can't have good intuitive grounds to believe it. I've only called attention to some complications. This is relevant to 6 , to which I now turn.

\subsection{The justification claim}

Call 6 the justification claim. It says that, for purposes of justifying punishment against the fact that it inflicts suffering, good enough reasons can be given for the value claim. I'll argue that the justification claim assumes a questionable standard of justification.

In the passage quoted at the end of Sect. 2, Berman argues that punishment is justified against the fact that it inflicts suffering because the value claim is very likely true. Following Davis, he argues that the value claim is very likely true because (A) there's no convincing argument against it and because (B) intuitions for it are widespread. Let's evaluate this argument, starting with A. Here's an argument against the value claim: It's intrinsically bad when people suffer, so the value claim is false. Berman finds this argument unconvincing. Why? I find it convincing because I have strong intuitions in favor of the premise and serious doubts about contrary intuitions. And I'm not the only one. ${ }^{12}$ Probably what Berman means when he says that such arguments are unconvincing (at least in the context of the quoted passage) is that those who have intuitions like his will find them unconvincing. But this does nothing to show that the value claim is very likely true. My guess is that A isn't meant to provide independent support for the value claim. Instead, it's meant to point out that there's nothing that undermines B's support for it.

If so, the argument's prospects turn on B. But B is questionable. It's not obvious how widespread intuitions for the value claim are. Even if they are widespread, that's not good evidence that the value claim is very likely true, since they might not be strong or stable enough. Berman must maintain that the intuitions are sufficiently widespread, strong, and stable to establish the value claim's likely truth. He-and retributivists generally-provide little to no evidence for this.

This counts against the justification claim. Retributivists don't provide the data needed to make a good case for the value claim. Their arguments are long on speculation and short on data. But this problem may be resolvable. Maybe we'd find that the requisite intuitions are widespread, strong, and stable if we investigated. I have no argument that they aren't. Nor do I have an argument that this wouldn't establish the likely truth of the value claim.

Establishing the likely truth of the value claim isn't obviously sufficient to establish the justification claim, though. This is the problem I want to focus on. First, consider an analogy. Suppose jurors in a criminal trial are given evidence that makes the defendant's guilt seem very likely. This doesn't justify conviction. Conviction is justified only if a reasonable person couldn't doubt the defendant's

\footnotetext{
12 See, e.g., Benn and Peters (1959, pp. 175-176), Bentham (1843, p. 390), Fingarette (1977, p. 503), Hampton (1984, pp. 236-237), Tadros (2011, pp. 73-78). Instructors who've discussed Retributivism in class have likely had students who say that the value claim seems false to them. Tadros repeatedly calls claims like the value claim barbaric. I agree with his assessment. I'm not saying this to hurl insults, but to emphasize just how strong the intuitive disagreement here can be.
} 
guilt on the evidence presented. For the purposes of rendering a verdict, jurors must presume the defendant's innocence. They can abandon the presumption and convict only if the prosecution proves the key elements of its case beyond a reasonable doubt [BARD]. We use the BARD standard partly because weaker standards don't sufficiently reduce the chances of convicting and punishing innocent people. Convicting and punishing innocent people is a serious error. We think that great pains should be taken to avoid it.

Maybe we should hold justifications of punishment to a similar standard. On a BARD standard, Berman has justified punishment against the claim that it inflicts suffering-which is presumptively bad-only if a person couldn't reasonably doubt the value claim given Berman's argument for it. ${ }^{13}$ If BARD is the right standard to use, the justification claim is false. Some people have the intuition that the value claim is false and can reasonably doubt it on that basis. Others have the intuition that it's true, but can reasonably doubt it because their intuitions are too weak or unstable. Others may have strong, stable intuitions for it, but can reasonably doubt it for other reasons. For example, they can reasonably worry that their intuitions are the product of bias or error because other people who seem reasonable and morally sensitive have contrary intuitions.

Reasons to use BARD in criminal trials seem to apply here. At the least, an argument for a high standard seems attractive. Here's a sketchy version of such an argument. There are potential errors here that would be very serious. So, we should use a high standard to avoid them. There are at least two such errors. We could think that punishment is sometimes permissible, even though it isn't. Or we could be right that it's sometimes permissible, but be wrong about why. If we punish and punishment is impermissible, that's obviously a serious error. But punishing for the wrong reasons is too. Our reasons for punishing guide how we punish. Bad reasons give bad guidance. If we punish because we think that the value claim is true, and we're wrong, we'll likely make the world a lot worse. ${ }^{14}$ If we punish because we think that punishment is necessary to deter, and we're wrong, then at best we'll

\footnotetext{
13 Benjamin Vilhauer (2009) endorses using BARD to evaluate justifications of punishment (thanks to him for sharing his paper with me). I'll try to offer some support for this view below. Vilhauer (2009, p. 133) just assumes that justice requires that arguments for doing serious harm to people must be held to the BARD standard. He argues that retributivist justifications fail because they rely on a claim that can be reasonably doubted: that people have free will. I'm obviously sympathetic to Vilhauer's position. But for the record, I'm not sure if it can be reasonably doubted that people have free will. For now, I'm agnostic on that issue.

14 Potential bad consequences are only part of the problem here. They might not even be the most important part. Consider what Jonathan Quong says about mistakes of liability.
}

[M]aking a mistake about other people's liability to harm is different. When you assume that others are liable to bear the harm that your actions will impose, you treat those others as entitled to less than the level of concern and respect they are due, and as a result you must accept a special responsibility if you turn out to be mistaken. To treat others as if they lack rights is a grave matter, and this is why mistakes about other people's rights are different from other kinds of mistakes we might make. (2012, p. 77)

If we punish people because we think they have no right not to be punished, and we're wrong, that too is a very serious error. 
often punish in the wrong ways and at the wrong times. At worst, we'll needlessly engage in a very costly, harmful practice (cf. Husak 1992).

There's an obvious objection: there are important differences between criminal trials and the practice of punishment as a whole that make BARD a bad standard for evaluating justifications of punishment. The costs of using BARD in criminal trials are worth the benefit of avoiding serious errors. But one might worry that the potential costs of using it to evaluate justifications of punishment are too high. BARD would make it very hard-perhaps impossible - to justify punishment. If so, we might have to stop punishing, or at least punish much less. But one might complain that that would be unacceptable because we wouldn't be able to do things like deter wrongdoing, protect the innocent, and remedy injustice.

I'm not out to vindicate a particular standard, just to point out that the issue of standards hasn't received adequate attention. So I won't respond at length or flesh out the above argument. But it's worth mentioning one reason why I'm dubious about the objection. It apparently assumes that non-punitive methods of criminal justice are seriously limited. This is a widespread assumption. But it's false. Among others, David Boonin (2008), Geoffrey Sayre-McCord (2001), and I (see, e.g., Hanna in press a) have argued that there are alternatives that can do a lot to deter, protect innocents, and remedy injustice. If we're right, the objection arguably exaggerates the potential costs here. ${ }^{15,16}$

A related objection goes as follows. Perhaps the fact that BARD would be very hard or impossible to satisfy just makes it an inappropriate standard, irrespective of any risks associated with its use. One might simply assert this. Or one might draw an analogy with arguments for skepticism. Skeptical arguments sometimes rely on unacceptably high standards for knowledge. Maybe insisting on using a high standard here would be doing something similar. ${ }^{17}$

I'm not sympathetic to the assertion that BARD is an unacceptable standard if it would make punishment very hard or impossible to justify. If we have otherwise good reasons to use BARD and it turns out that it would be very hard or impossible for justifications of punishment to satisfy it, then so much the worse for punishment. We should examine the reasons for using BARD and ask whether they're good. If they are and if justifications of punishment can't satisfy BARD, then punishment is unjustified.

\footnotetext{
15 Of course, such alternatives would have to be justified too. But for all the above objection shows, it might be that they should be held to a lower standard. I'm optimistic that some such alternative can meet the BARD standard, however.

16 Another objection is that I'm overlooking a risk of error that supports a weaker standard. Some retributivists say that it's bad when wrongdoers go unpunished. If they're right, using a strong standard increases the likelihood that we'll mistakenly refrain from punishing people who should be punished. In response, I don't think that this particular risk shows that using a strong standard is inappropriate. It's widely accepted that punishing people who aren't fit subjects of punishment is much worse that not punishing people who are (that's why we use BARD in criminal trials). If so, the risks I'm appealing to are more serious. Moreover, the risk the objection appeals to can be mitigated by using non-punitive enforcement. Even if it's bad when wrongdoers aren't punished, it's not obvious how bad it would be to subject them only to non-punitive methods like those mentioned above.

17 Thanks to Dan Meyer for these objections.
} 
As for the analogy with skepticism, I think it's misguided. This is because the reasons I've given for using a high standard here are special. I'm not saying that we should use a high standard like BARD to decide whether to believe claims like the value claim. So far as I've said, many people might be justified in believing such claims. What I'm saying is that we might want to use a high standard like BARD to decide whether the arguments and evidence for such claims are good enough to justify doing something specific on the basis of them: engaging in the practice of punishment. Justifications of punishment don't just argue for the truth of certain claims. They offer these claims in defense of engaging in this practice. Because of this, and because of special and highly worrisome facts about this practiceincluding the risks of error I discussed-we should require a high degree of confidence in our reasons for engaging in it. We should tolerate much less fallibility in this context than we do in others.

Suppose that BARD is too strong for some reason, though. Some other strong standard might still be appropriate, e.g., something like the clear and convincing evidence standard [CACE]. CACE is satisfied if the evidence for a claim makes it substantially more likely to be true than not and if the evidence for it generates a firm belief in the trier of fact. How does the justification claim fare under CACE? If retributivist arguments are as speculative as I've claimed, not well. But if the requisite data were provided, things would be less clear. Things would turn on the degree of likelihood implicated in the standard and what the analogue of a trier of fact is here. If people with anti-retributive intuitions or people who reasonably doubt their retributive intuitions are among the triers of fact (as I think they should be) and if the likelihood is high (as I think it should be) then the prospects don't look good.

In short, there are apparently compelling reasons to think that we should use a high standard of justification to evaluate justifications of punishment. And it's not obvious that retributivist justifications can satisfy a high standard.

My objection casts new light on a familiar criticism of Retributivism. Antiretributivists traditionally criticize retributivist appeals to intuition. Retributivists typically reply that appealing to intuitions is unavoidable in moral and political theory and that anti-retributivists do it too. ${ }^{18}$ This reply has always seemed too quick to me. The most charitable construal of the criticism is in terms of standards of justification. So construed, the criticism is that retributivist intuitions, for whatever reason, don't satisfy whatever the right standard is here. The critics sometimes try to illustrate this by raising doubts about the intuitions. For example, they sometimes propose hypotheses about these intuitions' problematic origins. Or they emphasize the fact that others have very different intuitions. These critics typically endorse justifications that appeal to intuitions that they take to be less doubtful.

Consequentialist advocates of punishment have been among the most vocal critics of this sort. But my discussion should give them no comfort. This is because consequentialist justifications must also satisfy whatever the right standard is here. And they don't obviously satisfy high standards like BARD or CACE. This is because they typically rely on speculative claims about punishment's deterrent

\footnotetext{
18 Berman (p. 270) criticizes Herbert Fingarette (1977) on this score. Davis (1972, p. 140) says something similar, anticipating Jan Narveson's (1974, p. 193) complaints.
} 
efficacy, e.g., that punishment deters substantially more than alternatives can. As I've argued elsewhere, the evidence for such claims isn't compelling (Hanna in press a; cf. Sayre-McCord 2001, pp. 515-516). If we should use a high standard of justification to evaluate justifications of punishment, I think that all extant justifications will be found wanting.

\section{Conclusion}

To sum up, Berman has helpfully illuminated the structure of justification: it's specific and must be tailored to particular demand bases. But he has said-and punishment's advocates in general say-little about standards of justification. Berman's claims about structure are compatible with different standards, including ones on which the justification claim is false or at least not obviously true. The justification claim just assumes a questionable standard of justification.

Retributivists overlook this issue. This is a serious gap in extant versions of Retributivism - and in all extant justifications of punishment.

Acknowledgments Thanks to Mitchell Berman, Dan Meyer, Katherine Valde, Benjamin Vilhauer, and several anonymous referees. Thanks also to an audience at the 2012 Northwest Philosophy Conference at Oregon State University, where I presented a shorter version of this paper. I also presented a distant ancestor of it at a dissertation workshop at Syracuse University in 2007. Thanks to the participants, especially Ernesto Garcia, Mark Heller, John Monteleone, and Paul Prescott.

\section{References}

Benn, S., \& Peters, R. S. (1959). Social principles and the democratic state. London: George Allen \& Unwin Ltd.

Bentham, J. (1843). Principles of penal law. In J. Bowring (Ed.), The works of Jeremy Bentham (vol. 1). London: Simpkin, Marshall.

Berman, M. (2008). Punishment and Justification. Ethics, 118, 258-290.

Boonin, D. (2008). The problem of punishment. New York: Cambridge University Press.

Braithwaite, J., \& Pettit, P. (1990). Not just deserts. New York: Oxford University Press.

Davis, L. (1972). They deserve to suffer. Analysis, 32, 136-140.

Dolinko, D. (1991). Some thoughts about retributivism. Ethics, 101, 537-559.

Fingarette, H. (1977). Punishment and suffering. Proceedings and Addresses of the American Philosophical Association, 50, 499-523.

Freiman, C., \& Nichols, S. (2011). Is desert in the details? Philosophy and Phenomenological Research, $82,121-133$.

Gardner, J. (1996). Justifications and reasons. In A. Simester \& A. T. H. Smith (Eds.), Harm and culpability. Reprinted in J. Gardner. (2007). Offences and defences. New York: Oxford University Press.

Hampton, J. (1984). The moral education theory of punishment. Philosophy \& Public Affairs, 13, 208-238.

Hanna, N. (2009). The passions of punishment. Pacific Philosophical Quarterly, 90, 232-250.

Hanna, N. (a). Facing the consequences. Criminal Law and Philosophy (in press).

Hanna, N. (b). Two claims about desert. Pacific Philosophical Quarterly (in press).

Huemer, M. (2005). Ethical intuitionism. New York: Palgrave MacMillan.

Husak, D. (1992). Why punish the deserving? Noûs, 26, 447-464.

Kleinig, J. (1973). Punishment and desert. The Hague: Martinus Nijhoff.

Marks, G., \& Miller, N. (1987). Ten years of research on the false-consensus effect: An empirical and theoretical review. Psychological Bulletin, 102, 72-90. 
Moore, M. (1987). The moral worth of retribution. In F. Schoeman (Ed.), Responsibility, Character, and the Emotions: New Essays in Moral Psychology. Cambridge: Cambridge University Press.

Moore, M. (1993). Justifying retributivism. Israel Law Review, 27, 15-49.

Narveson, J. (1974). Three analysis retributivists. Analysis, 34, 185-193.

Quong, J. (2012). Liability to defensive harm. Philosophy \& Public Affairs, 40, 45-77.

Robinson, P. H., \& Kurzban, R. (2006-2007). Concordance and conflict in intuitions of justice. Minnesota Law Review, 91, 1829-1907.

Sayre-McCord, G. (2001). Criminal justice and legal reparations as an alternative to punishment. Philosophical Issues, 11, 502-529.

Tadros, V. (2011). The ends of harm. New York: Oxford University Press.

Vilhauer, B. (2009). Free will and reasonable doubt. American Philosophical Quarterly, 46, 131-140. 